\title{
AVALIAÇÃO IN VITRO DO EFEITO DE RIZOBACTÉRIAS SOBRE MELOIDOGYNE INCOGNITA, M. JAVANICA E PRATYLENCHUS ZEAE
}

\author{
G.C.S. Alves ${ }^{1}$, J.M. dos Santos, P.L.M. Soares ${ }^{2}$, F.G. de Jesus ${ }^{3}$, E.J, de Almeida²*, R.T. Thuler ${ }^{4}$ \\ ${ }^{1}$ Universidade Federal de Goiás, Escola de Agronomia e Engenharia de Alimentos, CP 131, CEP 74690-900, \\ Goiânia, GO, Brasil. E-mail: gleinacosta@yahoo.com.br
}

\section{RESUMO}

\begin{abstract}
Considerando as perdas causadas por nematoides às diversas culturas, as rizobactérias se apresentam como uma alternativa para manejar esse patógenos. Assim, o objetivo deste trabalho foi avaliar in vitro a ação de 20 isolados de rizobactérias sobre a eclosão e a motilidade de juvenis de segundo estádio de Meloidogyne incognita e M. javanica e sobre a motilidade de Pratylenchus zeae. O experimento foi instalado em condições de laboratório e em delineamento inteiramente casualizado com quatro repetições, constituídas por uma câmara de eclosão cada. As avaliações foram realizadas a cada 72 horas. Após as avaliações observou-se que nenhum dos isolados avaliados influenciaram a eclosão de $M$. incognita, entretanto para $M$. javanica, os isolados FCAV 8 e FCAV 10 proporcionaram pronunciada ação ovicida. Entre os isolados testados sobre a motilidade dos nematoides-das-galha apenas os isolados de Bacillus amyloliquefaciens e B. subtillis evidenciaram potencial como agente do controle de juvenis de segundo estádio de M. javanica. Quando se avaliou a motilidade dos isolados sobre espécimes ativos de P. zeae, obsevou-se que os isolados FCAV 5, FCAV 7 e B. amyloliquefaciens exibiram potencial como agentes do controle biológico de P. zeae. Estes resultados confirmam que entre as rizobactérias podem ser encontrados agentes eficazes para o controle de nematoides.
\end{abstract}

PALAVRAS-CHAVE: Nematoide-das-galhas, nematoide-das-lesões-radiculares, motilidade, controle biológico.

\section{ABSTRACT}

IN VITRO ASSESSMENT OF THE EFFECT OF RHIZOBACTERIA ON MELOIDOGYNE INCOGNITA, M. JAVANICA AND PRATYLENCHUS ZEAE. Considering the losses caused by nematodes to different host plant, rhizobacteria are presented as an alternative to to control uch pathogens. So the goal of this study was to evaluate in vitro the action of 20 isolates of rhizobacteria on hatching and motility of second stage juveniles of the Meloidogyne incognita and M. javanica and on the motility of Pratylenchus zeae. The experiment was conducted under laboratory conditions and in a completely randomize design with four replications, and each experimental plot was represented by a hatching chamber. Measurements were spaced every 72 hours. After the evaluations showed that the isolates not influenced the emergence of $M$. incognita, M. javanica entertaining for isolates FCAV FCAV 8 and 10 showed pronounced ovicidal action. Among the isolates tested on the motility root-knot nematode, only isolates of Bacillus amyloliquefaciens and $B$. subtilis showed potential as an agent for control of second stage juveniles of $M$. javanica. When we assessed the motility of isolated active on specimens of $P$. zeae isolates the FCAV 5, 7 and FCAV B.amyloliquefaciens exhibited potential as agents of biological control of $P$. zeae. These results confirm that among the rhizobacteria may be found effective agents for the control of nematodes.

KEY WORDS: Root-knot nematode, root-lesion nematode, motility, biological control.

\section{INTRODUÇÃO}

As rizobactérias promotoras do crescimento de plantas (RPCP) ou 'Plant Grown Promter Rizobac- teria' (PGPR) são bactérias de solo que colonizam as raízes. São epifíticas ou endofíticas, não patogênicas, que promovem o crescimento e a bioproteção de plantas (MARIANO et al., 2004) e podem representar

${ }^{2}$ Universidade Estadual Paulista, Faculdade de Ciências Agrárias e Veterinárias, Jaboticabal, SP, Brasil.

${ }^{3}$ Instituto Federal Goiano, Urutaí, GO, Brasil.

${ }^{4}$ Instituto Federal de Educação, Ciência e Tecnologia do Triângulo Mineiro, Uberaba, MG, Brasil.

*Pós-Doutorando Fapesp. 
$10 \%$ da população de micro-organismos na região da rizosfera (RoBBs, 1991). A promoção de crescimento das plantas pode ser direta, por meio do aumento da taxa de germinação, crescimento de raízes, tubérculos, caules e colmos, além dos aumentos na floração e no rendimento (Luz, 1996). Esses efeitos são resultantes da produção de fitormônios, ácido cianídrico, enzimas, como a ACC-deaminase. Além disso, outros processos resultantes da ação de rizobactérias podem estimular o crescimento das culturas, tais como, fixação do nitrogênio da atmosfera, mineralização de nutrientes, solubilização de fósforo, oxidação de enxofre, aumento da permeabilidade das raízes, estímulo à absorção de nutrientes e a produção sideróforos. (ENEBAK et al., 1998). A ação benéfica das rizobactérias, também, pode ser indireta por meio do controle de microorganismos patogênicos (Luz, 1996). Quando a planta é infectada por um patógeno, as rizobactérias podem atuar como agentes de controle biológico, por meio da produção de metabólitos bacterianos tais como, antibióticos e enzimas que degradam a parede celular do patógeno afetando-o diretamente (ENEBAK et al., 1998). Os produtos do metabolismo dessas bactérias podem agir diretamente sobre a motilidade e/ou sobrevivência de embriões no interior dos ovos e diferentes estádios de desenvolvimentos dos nematoides (CAMPos et al., 1998).

Algumas PGPR's são produtoras de enzimas líticas, como quitinases e proteases que degradam as paredes de ovos de espécies de Meloidogyne, enquanto outras atrasam a eclosão de juvenis de segundo estádio $\left(\mathrm{J}_{2}\right)$, causam a mortalidade de formas infectantes dos nematoides ou interferem no processo de reconhecimento da planta hospedeira (SPIEGEL et al., 1990).

Ensaios in vitro têm demonstrado os efeitos de metabólitos sobre a eclosão e motilidade de juvenis (CAmpos et al., 1998). Cerca de 1\% de mais de 5.000 isolados de rizobactérias obtidos de diferentes plantas apresentaram habilidade de produzirem compostos e causarem a inibição completa ou parcial do movimento dos $\mathrm{J}_{2}$ de $M$. incognita, e $20 \%$ desses também reduziram o número de galhas em raízes de pepino, em casa de vegetação (BECKER et al., 1998).

Considerando a diversidade de vida no solo e suas estreitas associações entre os diferentes grupos de micro-organismos, podendo ter interações sinérgicas de predação ou parasitismo que promovem a bioproteção e crescimento das plantas, não se deve ignorar o potencial do controle biológico das rizobactérias promotoras do crescimento de plantas no controle de nematoides como opção eficaz para o manejo desses fitopatógenos.

O objetivo deste trabalho foi avaliar in vitro a ação de 20 isolados de rizobactérias sobre a eclosão e motilidade de $\mathrm{J}_{2}$ de Meloidogyne incognita (Kofoid
\& White) Chitwood e M. javanica (Treub) Chitwood e sobre a motilidade de formas ativas de Pratylenchus zeae Graham. Buscando informações sobre possíveis agentes de controle biológico para nematoides de relevância entre várias culturas de importância econômica para o país.

\section{MATERIAL E MÉTODOS}

\section{Obtenção das subpopulações dos nematoides}

As subpopulações de M. incognita e de M. javanica foram recuperadas deraízes infectadas de algodoeiro, da região de Barreiras (BA) e de quiabeiro da região de Piacatu (SP), respectivamente. As espécies foram previamente identificadas com base nos caracteres morfológicos do padrão perineal, preparadoconforme TAYLOR; NETSChER (1974), e na morfologia da região labial dos machos, conforme EIsENBACK et al. (1981). Essas subpopulações foram mantidas em plantas de tomateiro (Solanum lycopersicon) 'Santa Cruz Kada', em vasos de cerâmica com capacidade para seis litros, contendo uma mistura de terra e areia na proporção 1:2, previamente autoclavada, em casa de vegetação. A subpopulação de $P$. zeae foi recuperada de raízes de plantas de cana-de-açúcar da região de Pontalinda, SP, identificada com base nos caracteres morfológicos de fêmeas adultas, segundo GonZAGA (2006).

A partir das raízes de tomateiro exibindo galhas, cerca de 60 dias após a inoculação, foi preparada uma suspensão contendo ovos e $\mathrm{J}_{2}$ para cada uma das espécies dos nematoides de galha (HuSSEY; BARKER, 1973). A concentração de ovos e de juvenis de segundo estádio nessas suspensões foi estimada com auxílio de uma câmara de contagem de Peters, em um microscópio fotônico (SOUTHEY, 1970) e ajustado para 4.000 ovos e $_{2} / \mathrm{mL}$. Com o restante das suspensões, foram montadas câmaras de eclosão, segundo a metodologia descrita por ClifF; HIRSCHMANN, (1985), sendo que cada câmara continha $20 \mathrm{~mL}$ da suspensão de ovos. Para a obtenção de suspensões de $\mathrm{J}_{2,}$ estas câmaras foram incubadas por cinco dias.

Após a obtenção das suspensões de $\mathrm{J}_{2}$ estas foram colocadas em um funil de Baermann (SOUTHEY, 1970), para obtenção apenas dos $\mathrm{J}_{2}$ móveis. As coletas dos juvenis eram realizadas a cada 24 horas, sendo necessárias três coletas para obtenção da quantidade de $_{2}$ desejada. As suspensões coletadas do funil eram mantidas em geladeira a $5^{\circ} \mathrm{C}$, até a próxima coleta. A concentração da nova suspensão de $\mathrm{J}_{2}$ foi ajustada para $1.500 \mathrm{~J}_{2} / \mathrm{mL}$. A partir de raízes de plantas de cana-de-açúcar coletadas a campo foi obtida a suspensão de $P$. zeae pela técnica de Coolen; D'Herde (1972). A concentração da suspensão de formas ativas foi estimada e ajustada para 300 formas ativas / mL, conforme anteriormente descrito. 


\section{Preparo das suspensões bacterianas}

Nessa fase o experimento foi dividido em dois ensaios distintos. Com dois grupos diferentes isolados de rizobactérias. O primeiro grupo bacteriano foram codificados como, FCAV 1, FCAV 2, FCAV 3, FCAV 4, FCAV 5, FCAV 6, FCAV 7, FCAV 8, FCAV 9 e FCAV 10, foram provenientes da coleção de rizobactérias do laboratório de Nematologia do Departamento de Fitossanidade da Faculdade de Ciências Agrárias e Veterinárias - Universidade Estadual Paulista (FCAV - UNESP), Câmpus de Jaboticabal, SP. O segundo grupo de rizobactérias foram oriundos do laboratório de Fitobacteriologia da Universidade Federal Rural de Pernambuco (UFRPE), compreendendo os seguintes isolados: Alcaligenes piechaudii, B. amyloliquefaciens, B. cereus, $B$. thuringiensis kenyae. Bacillus megaterium pv. cerealis, B. pumilus, B. subtillis, B. thuringiensis kurstakii, Enterobacter cloacae e Kluyvera ascorbata.

As rizobactérias foram multiplicadas em placas de Petri de plástico de $90 \mathrm{~mm}$ de diâmetro, esterilizadas com raios gama, contendo meio de cultura TSA "Trypic Soy Agar" e incubadas por 20 horas a $28^{\circ} \mathrm{C}$, em câmara de crescimento do tipo B.O.D. Em seguida, as placas eram levadas à câmara de fluxo laminar, onde as culturas bacterianas foram ressuspendidas em água esterilizada, com o auxílio de uma alça de Drigalsk. Cada suspensão bacteriana foi adicionada, separadamente, a um erlenmeyer de vidro contendo $160 \mathrm{~mL}$ de água autoclavada. E, com o auxílio de um espectrofotômetro foi preparada uma nova suspensão aquosa ajustada para densidade ótica $\mathrm{OD}_{625}=0,2$, para os isolados provenientes da FCAV/UNESP.

Para os isolados bacterianos provenientes da UFRPE, a suspensão aquosa foi a justada para uma densidadeótica $\mathrm{OD}_{625}=0,7$, devido resultados promissores obtidos com estudos preliminares realizados para insetos.

Efeito de isolados de rizobactérias sobre a eclosão de juvenis de Meloidogyne incognita e de M. javanica

Após determinada a densidade ótica das suspensões bacterianas, $20 \mathrm{~mL}$ da suspensão de cada isolado foi adicionada, separadamente, à câmaras de eclosão, para avaliação da influência destes isolados bacterianos sobre a eclosão dos juvenis de M. incognita e de M. javanica. A eclosão desses nematoides em água foi utilizada como controle.

A seguir, $1 \mathrm{~mL}$ da suspensão contendo 4.000 ovos dos nematoides foi adicionado, individualmente, a cada uma das câmara de eclosão. As câmaras contendo as suspensões de rizobactérias e água, ovos de M. incognita e de M. javanica foram mantidas por nove dias no escuro, em B.O.D a $28 \pm 1^{\circ} \mathrm{C}$, para os isolados FCAV 1, FCAV 2, FCAV 3, FCAV 4, FCAV 5, FCAV 6, FCAV 7, FCAV 8, FCAV 9 e FCAV 10. Para os isolados de Alcaligenes piechaudii, $B$. amyloliquefaciens, B. cereus, B. thuringiensis kenyae, Bacillus megaterium pv. cerealis, B. pumilus, B. subtillis, B. thuringiensis kurstakii, Enterobacter cloacae e Kluyvera ascorbata o tempo de incubação na B.O.D foi de seis dias. Esse período de avaliação menor que o período de avaliação do grupo das rizobactérias provenientes da FCAV/UNESP foi devido a uma desintegração do papel filtro, utilizado na confecção da câmara de eclosão, após o sexto dia, assim, uma avaliação a mais, aos 9 dias, poderia ter os resultados comprometidos.

Emintervalos regulares de 72 horas, as suspensões de $\mathrm{J}_{2}$ das câmaras de eclosão foram recuperadas, com o auxílio de pipeta de Pasteur e transferidas para béqueres de $100 \mathrm{~mL}$. Em seguida igual volume da suspensão bacteriana ou deágua foi reposto em cada câmara. Posteriormente estimou-se a população de $\mathrm{J}_{2}$ em cada suspensão ao microscópio fotônico, com auxílio da câmara de contagem de Peters (SOUTHEY, 1970). Determinaram-se os percentuais de eclosão de $\mathrm{J}_{2} \mathrm{e}$, para efeito de comparação entre os tratamentos, a taxa de eclosãoemágua (testemunha) foi considerada como $100 \%$, comparando os demais tratamentos com a testemunha. O delineamento experimental foi o inteiramente casualizado, com quatro repetições, sendo cada uma delas constituída por uma câmara de eclosão. Como os dados não atendiam a distribuição normal estes foram transformados para raiz $(x+0,5)$, submetidos à análise de variância pelo Teste $\mathrm{F}$ e as médias foram comparadas pelo teste de Scott-knott a $\mathrm{p}>0,05$ de probabilidade.

Efeito de isolados de rizobactérias sobre a motilidade de juvenis de Meloidogyne incognita, de $M$. javanica e de Pratylenchus zeae.

Os mesmos isolados bacterianos foram empregados para o estudo da ação dessas rizobactérias sobre a motilidade de J2 de $M$. incognita e de $M$. javanica e sobre formas ativas de P. zeae. Foi determinada a densidade ótica de cada uma das suspensões bacterianas aquosas como descrito anteriormente. A seguir, $20 \mathrm{~mL}$ da suspensão de cada isolado foram adicionados, separadamente, a cada uma das câmaras de eclosão (CLIFF; HiRsCHMANN, 1985), a água foi utilizada como controle. Às câmaras foram adicionado, separadamente, $1 \mathrm{~mL}$ de suspensão de $\mathrm{J}_{2}$ de $M$. incognita e de $M$. javanica, contendo 1.500 espécimes / $\mathrm{mL}$ e $1 \mathrm{~mL}$ de suspensão de $P$. zeae, contendo 300 espécimes/mL, obtidos como anteriormente descrito. A seguir, essas câmaras foram mantidas por nove dias no escuro, em B.O.D a 28 $\pm 1^{\circ} \mathrm{C}$ para os isolados FCAV 1, FCAV 2, FCAV 3, 
FCAV 4, FCAV 5, FCAV 6, FCAV 7, FCAV 8, FCAV 9 e FCAV 10 Para os demais isolados seguiu-se a mesma metodologia, variando apenas a leitura da densidade óptica $\mathrm{OD}_{625}=0,7$ e o tempo de imersão, que foi de seis dias.

O delineamento experimental e as avaliações seguiram a mesma metodologia do item anterior. Entretanto, para se estimar o número de indivíduos móveis ou imóveis $1 \mathrm{~mL}$ de solução $1 \mathrm{~N}$ de $\mathrm{NaOH}$ foi adicionado a $10 \mathrm{~mL}$ da suspensão de nematoides e, imediatamente utilizando-se a câmara de contagem de Peters foi estimado ao microscópio fotônico a população de formas móveis e imóveis, conforme CHen; Dickson (2000).

Os dados não atendiam a distribuição normal estes foram transformados para raiz $(x+0,5)$, submetidos à análise de variância pelo Teste $\mathrm{F}$ e as médias foram comparadas pelo teste de Scott-knott a $\mathrm{p}>0,05$ de probabilidade.

\section{RESULTADOS E DISCUSSÃO}

Efeito de isolados de rizobactérias sobre a eclosão de juvenis de Meloidogyne incognita e de M. javanica

Os dados referentes à imersão dos ovos de $M$. incognita e M. javanica, em suspensões dos isolados bacterianos FCAV 1, FCAV 2, FCAV 3, FCAV 4, FCAV 5, FCAV 6, FCAV 7, FCAV 8, FCAV 9 e FCAV 10 por nove dias (Fig. 1A) evidenciaram que para $M$. incognita os isolados não diferiram estatisticamente entre si, nem em relação a testemunha (água). Entretanto para $M$. javanica, observou-se maior ação ovicida dos isolados FCAV 2, FCAV 6, FCAV 8 e FCAV 10, diferiram dos demais isolados, da testemunha enão diferiram estatisticamente entre si. Para melhor apresentação dos resultados, porcentagens foram calculadas, com as médias originais apresentadas na Figura 1. Para esse cálculo a testemunha foi considerada como $100 \%$. Os isolados FCAV 2, FCAV 6, FCAV 8 eFCAV 10, Proporcionaram uma redução na porcentagem de eclosão de $53,5 \%$ para o isolado FCAV 2, 40,50\% para o isolado FCAV 6, 75,3\% para o isolado FCAV 8 e $64,5 \%$ para p isolado FCAV 10, quando comparados a testemunha.

Na imersão dos ovos de M. incognita e M. javanica em isolados bacterianos de Alcaligenes piechaudii, $B$. amyloliquefaciens, B. cereus, $B$. thuringiensis kenyae, $B$. thuringiensis kurstakii, Enterobacter cloacae e Kluyvera ascorbata. por 6 dias, não houve diferença estatística significativa quanto à eclosão de juvenis de $M$. incognitae $M$.javanica entre os isolados e testemunha em nenhuma avaliação (Fig. 1B).

Como no presente trabalho, OOSTENDORP; SIKORA (1990) também observaram completa inibição da eclosão de Heterodera schachtii por filtrados de culturas bacterianas. Por outro lado, o contato direto da calda contendo $B$. subtilis com juvenis de $H$. glycines, recém-eclodidos, não ocasionou redução significativa da população de nematoide após sete dias de incubação.
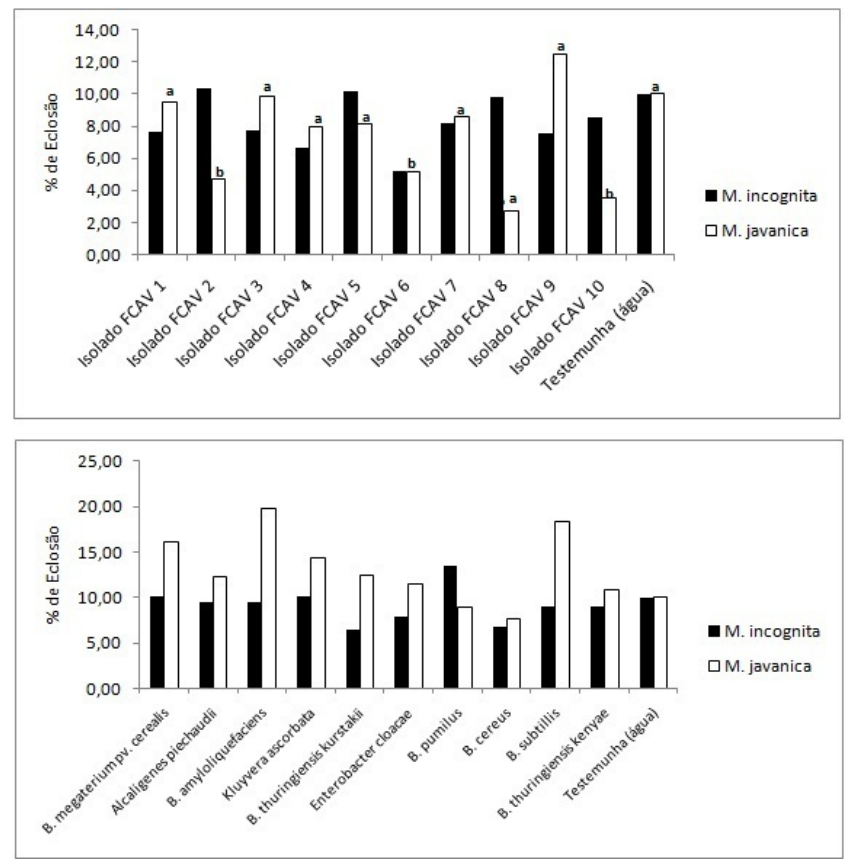

Fig. 1 - Médias da eclosão de J2 de Meloidogyne incognita e M. javanica imersos em suspensões de diferentes isolados de rizobactérias in vitro. A) Ovos imersos por nove dias (densidade ótica $\mathrm{OD}_{625}=0,2$ ). M. incognita F: 0,31 CV: 61,29\% e $M$. javanica F: 5,27 CV: 30,87\%. B) Ovos imersos por seis dias (densidade ótica OD $625=0,7$ ). M. incognita F: 1,73 CV: 21,91\% e M. javanica F: 1,65 CV: 32,57\%. Dados transformados em raiz de (x+0,5). Médias seguidas da mesma letra não diferem estatisticamente entre si, pelo teste de Scott-knott a $5 \%$. 
Contrariando estes resultados, HuAng et al. (2010) observou que as substâncias químicas produzidas por B. megaterium, tem potencial ação nematicida contra M. incognita, chegando a inibir $100 \%$ da eclosão dos juvenis.

Araújo et al. (2002) trabalhando com B. subtilis, conseguiu reduzir significativamente a eclosão de juvenis de $H$. glycines in vitro, quando comparou os exsudados tratados e não tratados com a bactéria. Os mesmos autores concluíram que o mecanismo envolvido no estímulo à eclosão deve estar relacionado a metabólitos produzidos no desenvolvimento da bactéria, pois a utilização de células separadamente não proporcionou a mesma redução encontrada quando foi utilizado a calda com a bactéria.

Efeito de isolados de rizobactérias sobre a motilidade de juvenis de Meloidogyne incognita e $M$. javanica e de Pratylenchus zeae

Na avaliação da atividade dosjuvenis de segundo estádio de $M$. incognita e $M$. javanica imersos por nove dias nos isolados bacterianos FCAV 1, FCAV 2, FCAV 3, FCAV 4, FCAV 5, FCAV 6, FCAV 7, FCAV 8, FCAV 9 e FCAV 10 (Fig. 2 - A) não houve diferença estatística entre os isolados quanto à percentagem de juvenis imóveis, ou supostamente mortos, para nenhum dos nematoides de galhas avaliados.

Na imersão de J2 de $M$. incognita por seis dias em suspensões dos isolados bacterianos Alca- ligenes piechaudii, B. amyloliquefaciens, B. cereus, $B$. thuringiensis kenyae, Bacillus megaterium pv. cerealis, B. pumilus, B. subtillis, B. thuringiensis kurstakii, Enterobacter cloacae e Kluyvera ascorbata. (Fig. 2B) observou-se que os isolados de $B$. cereus e $B$. thuringiensis kenyae proporcionaram as menores percentagens em relação aos juvenis imóveis de $M$. incognita. O isolado de $B$. cereus diferiu da testemunha. Nesse caso também se calculou a porcentagem do controle, usando as médias, a testemunha foi considerada como $100 \%$ (Fig. 2), Os isolados que apresentaram maior efeito nocivo aos juvenis foram os isolados de $B$. amyloliquefaciens e $B$. subtillis, aumentando a motilidade desses nematoides em $310,34 \%$ e $282,18 \%$ respectivamente, quando comparados a testemunha. Esses resultados evidenciam o potencial do isolado de B. amyloliquefaciens como agente no controle biológico de $M$. incognita.

Esses isolados bacterianos não proporcionaram diferenças estatísticas para M. javanica (Fig. 2B). Fica evidente, na pesquisa, a especificidade das bactérias em relação aos nematoides, uma vez que os que se apresentam mais eficientes para o controle de $M$. javanica não foram os mesmos para M. incognita.

FreITAS (2008) também obtiveram redução de $53 \%$ no número de galhas formadas por $M$. incognita em raízes de tomateiro, utilizando uma mistura de Pseudomonas spp. fluorescentes, três Pseudomonas spp. não fluorescentes e um Bacillus spp.

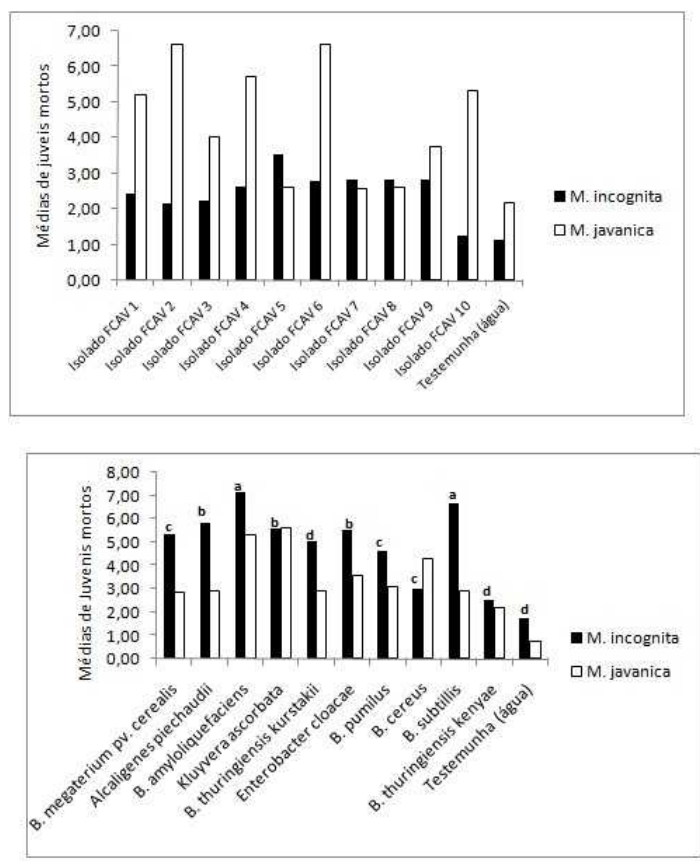

Fig. 2 - Médias de J2 de Meloidogyne incognita e M. javanica imóveis, ou supostamente mortos imersos em suspensões de diferentes isolados de rizobactérias in vitro. A) J2 imersos por nove dias (densidade ótica $\left.\mathrm{OD}_{625}=0,2\right)$. M. incognita $\mathrm{F}$ : 0,26 CV: 99,99\% e M. javanica F: 2,11 CV: 47,00\%. B) J2 imersos por seis dias (densidade ótica OD $625=0,7$ ). M. incognita F: 139,37 CV: 4,25\% e M. javanica F: 0,80 CV: 66,74\%. Dados transformados em raiz de (x + 0,5). Médias seguidas da mesma letra não diferem estatisticamente entre si, pelo teste de Scott-knott a $5 \%$. 
SidDiQui et al. (2001) também verificaram por meio de testes in vitro um efeito nematicida de diferentes isolados de Pseudomonas aeruginosa e B. subtilis sobre juvenis de segundo estádio de $M$. javanica e zonas de inibição do crescimento de Macrophomina phaseolina, Fusarium solani e Rhizoctonia solani. Os autores observaram, ainda, em casa de vegetação e campo, diferentes níveis de supressão da infecção causada por tais fungos e pelos nematoides em Vigna radiata.

Sousa et al. (2006), realizando bioensaios in vitro com isolados da bactéria filamentosa Streptomyces sp. (AC-26), Streptomyces griséus subsp. griséus (AC92) Streptomyces N0035 (AC-95), observaram um aumento da mortalidade dos $\mathrm{J} 2$, quando comparados com a testemunha.Streptomyces griseus subsp.griseus (AC-92) proporcionou 98,2\% de mortalidade dos J2, quando comparado aos $27,3 \%$ observados na testemunha, destacando-se como o isolado mais eficiente no controle de M. incognita in vitro.

Para melhor entendimento dos resultados, estes também foram calculados e apresentados em porcentagens com base nas médias originais. A testemunha foi considerada $100 \%$, na avaliação de isolados bacterianos em suspensão sobre espécimes de $P$. zeae imersos por nove dias aos diferentes isolados (FCAV 1, FCAV 2, FCAV 3, FCAV 4, FCAV 5, FCAV 6, FCAV 7, FCAV 8, FCAV 9 e FCAV 10).

Observou-se diferença estatística significativa entre os tratamentos FCAV 5 e FCAV 7, sendo que estes não diferiram entre si, mas diferiram de todos os demais tratamentos (Fig. 3A). Estes isolados foram os que menos permitiram a passagem dos nematoides pela câmara de eclosão, representando uma mortalidade de $532 \%$ em relação à testemunha. Quando se avaliou os isolados de B. megaterium pv. cerealis, A. piechaudii, B. amyloliquefaciens, K. ascorbata, B. thuringiensis kurstakii, E. cloacae, B. pumilus, B. cereus, $B$. subtillis e $B$. thuringiensis kenyae, sobre espécimes de $P$. zeae, evidenciou-se ação nematicida dos tratamentos B. megaterium pv.cerealis, A. piechaudii, B. amyloliquefaciens, K. ascorbata, B. thuringiensis kurstakii (Fig. 3B). Estes isolados foram os que menos permitiram a passagem do nematoide pela câmara de eclosão

Nos tratamentos referentes aos isolados FCAV 5 e FCAV 7 e B. amyloliquefaciens não foram recuperados espécimes de P.zeae durante o período de avaliação do experimento, o que indica que os isolados inativaram os nematoide ainda sobre $o$ papel na câmara de eclosão, impedindo sua movimentação. Por conseguinte, estes têm pronunciada ação nematicida sobre $P$. zeae mostrando-se agentes promissores do controle biológico dessa espécie de nematoide estudada.

DickLow et al., (1993) estudando o efeito de $S$ treptomyces costaricanus sobre $M$. incognita, Pratylenchus penetrans e Rotylenchus reniformis, observaram que a bactéria reduziu o número de galhas em raízes de pimenteira plantada em solo naturalmenteinfestado, bem como a população de $P$. penetrans em raízes de morango e a população de $R$. reniformis em tomateiro e pimenteira.
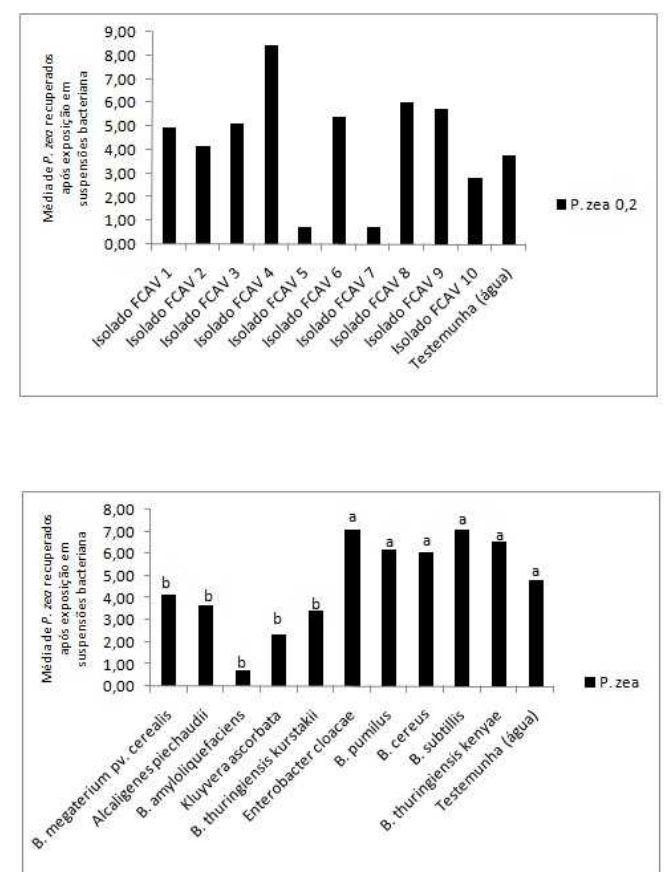

Fig. 3 - Médias de Pratylenchus zeae imóveis recuperados após imersão em suspensões de diferentes isolados de rizobactérias in vitro. A) P. zeae imersos por nove dias (densidade ótica $\left.\mathrm{OD}_{625}=0,2\right)$. F: 4,47 CV: 75,20\%. B) P. zeae imersos por seis dias (densidade ótica $\left.\mathrm{OD}_{625}=0,7\right)$. F: 4,22 CV: 30,34\%. Dados transformados em raiz de $(x+0,5)$. Médias seguidas da mesma letra não diferem estatisticamente entre si, pelo teste de Scott-knott a $5 \%$. 
Várias espécies de bactérias foram encontradas em solos na região da rizosfera de batatas e evidenciaram atividade antagonista aos nematoides das lesões radiculares (P. penetrans) (TIAN et al., 2007).

Os resultados apresentados no presente trabalho e na literatura corroboram com o mecanismo de ação publicado por FreITAS (2008) de que as rizobactérias interferem na formação do embrião, na eclosão, na mobilidade do nematoide e consequentemente interfere no reconhecimento do hospedeiro, o que interfere diretamente na alimentação ena reprodução dos fitonematoides.

\section{CONCLUSÃO}

Nas condições da presente pesquisa os isolados bacterianos FCAV 6 e FCAV 8 proporcionaram ação ovicida para M. javanica. Entretanto, não tiveram a mesma ação contra ovos de $M$. incognita. Entre os isolados testados sobre a motilidade dos nematoides de galhas, apenas os isolados de B. amyloliquefaciens e $B$. subitilis evidenciaram potencial como agente do controle de $\mathrm{J}_{2}$ de $M$. javanica. Os isolados FCAV 5, FCAV7eB. amyloliquefaciens mostroram-se eficientes no controle de $P$. zeae. Estes resultados confirmam que entre as rizobactérias podem ser encontrados agentes eficazes para o controle de nematoides.

\section{REFERÊNCIAS}

ARAÚJO, F.F.; VELOSO-SILVA, J.F.; ARAÚJO, A.S.F. Influência de $B$. subtilis na eclosão, orientação e infecção de Heterodera glycines em soja. Ciência Rural, v.32, p.197-202, 2002.

BECKER, J.O.; ZAVALETA-MEJIA, E.; COLBERT, S.F.; ACHROTH M.N.; WEINHOLD A.R, HANCOCK, J.G \& VAN GUNDY S.D. Effect of rhizobacteria on root-knot nematodes and gall formation. Phytopathology, v.78, p.1466-1469, 1998.

CAMPOS, V.P.; SOUZA, J.T.; SOUZA R.M. Controle de fitonematóides por meio de bactérias. Revisão Anual de Patologia de Plantas, v.6, p.285-327, 1998.

CHEN, S.Y.; DICKSON, D.W. A technique for determining live second-stage juveniles of Heterodera glycines. Journal of Nematology, v.32, p.117-121, 2000.

CLIFF, G.M.; HIRSCHMANN, H.H. Evaluation of morphological variability in Meloidogyne arenaria. Journal of Nematology, v.17, p. 445-449, 1985.

COOLEN, W.A.; D'HERDE, C.J. A method for the quantitative extraction of nematodes from plant tissue. Ghent: State Nematology and Entomology Research Station, 1972. 77p.
DICKLOW, M.B.; ACOSTA, N.; ZUCKERMAN, B.M. A novel Streptomyces species for controlling plant-parasitic nematodes. Journal of Chemical Ecology, v.19, p.159-173, 1993.

EISENBACK, J.D.; HIRSCHMANN, H.; SASSER J.N.; TRIANTAPHYLLOU, A.C. A guide to the four most common species of root-knot nematodes (Meloidogyne Species) with a pictorial key. Raleigh: North Carolina State University and United States Agency for International Development, 1981. 48p.

ENEBAK, S.A.; WEI, G.; KLOEPPER, J.W. Effects of plant growth-promoting rhizobacteria on loblolly and slash pine seedlings. Forest Science, v.44, p.139-144, 1998.

FREITAS, L.G. Rizobactérias versus Nematóides. Viçosa: UFV, 2008. 10p. Disponível em: <http://www.ufv.br/ $\mathrm{dfp} /$ lab/nematologia/rizo.pdf $>$. Acesso em: 12 mar. 2009.

GONZAGA, V. Caracterização morfológica, morfométrica e multiplicação in vitro das seis espécies mais comuns de Pratylenchus Filijev, 1936 que ocorrem no Brasil. 2006. $78 f$. Tese (Doutorado em Agronomia) - Faculdade de Ciências Agrárias e Vetrinárias, Jaboticabal. 2006.

HUANG, Y.; XU, C.; MA, L.; ZHANG, K.; DUAN, C.; $\mathrm{MO}, \mathrm{M}$. Characterisation of volatiles produced from Bacillus megaterium YFM3.25 and their nematicidal activity against Meloidogyne incognita. European Journal of Plant Pathology, v.126, p.417-422, 2010.

HUSSEY, R.S.; BARKER, K.R. A comparison of methods of collecting inocula of Meloidogyne spp. including a new technique. Plant Disease Reporter, v.57, p.1025-1028. 1973.

LUZ W.C. Rizobactérias promotoras de crescimento em plantas e bioproteção. Revisão Anual de Patologia de Plantas, v.4, p.1-49. 1996.

MARIANO R.L.R.; SILVEIRA E.B.; ASSIS S.M.P.; GOMES A.M.A.; NASCIMENTO A.R.P.; DONATO V.M.T. Importância de bactérias promotoras de crescimento e de biocontrole de doenças de plantas para uma agricultura sustentável. Anais da Academia Pernambucana de Ciência Agronômica, v.1, p.89-111, 2004.

OOSTENDORP, M.; SIKORA, R.A. In vitro interrelationships between rhizosphere bacteria and Heterodera schachtii. Revué de Nématologie, v.13, p.269-274, 1990.

ROBBS, C. Bactérias como potencial de controle biológico de Fitopatógenos. In: BETTIOL, W. (Ed.). Controle biológico de doenças de plantas. Jaguariúna: CNPDA/EMBRAPA, 1991. p.121-133.

SIDDIQUI, Z.A.; IQBAL, A.; MAHMOOD, I. Effects of Pseudomonas fluorescens and fertilizers on the reproduction of Meloidogyne incognita and growth of tomato. Applied Soil Ecology, v.16, n.2, p.179-185, 2001. 
SOUSA, C.S.; SOARES, A.C.F.; GARRIDO, M.S.;

ALMEIDA, G.M.C.O Estreptomicetos no controle da meloidoginose em mudas de tomateiro. Pesquisa Agropecuária Brasileira, v.41, p.1759-1766. 2006.

SPIEGEL, Y.; COHN, E.; GALPER, S.; LAPID, D.; SHARON, E.; CHET, I. Evaluation of chitinolytic microorganisms for controlling the root-knot nematode, Meloidogyne javani In: INTERNATIONAL NEMATOLOGY CONGRESS, 2., 1990, Veldhoven, Canadá. Abstracts. Veldhoven, 1990. p.141.
TAYLOR, A.L.; NETSCHER, C. An improved technique for preparing perinneal patterns of Meloidogyne spp. Nematologica, v.20, p. 268-269, 1974.

TIAN, B.; YANG, J.; ZHANG, K.Q. Bacteria used in the biological control of plant-parasitic nematodes: populations,mechanisms ofaction, and future prospects. Microbiology Ecology, v.61, p.197-213, 2007.

Recebido em 19/5/11

Aceito em 31/10/11 